\title{
E-LEARNING SYSTEMS FOR TEACHING INDUSTRIAL AUTOMATISM
}

Ala Balti National Higher Engineering School of Tunis, ENSIT, University of Tunis, Tunisia E-mail: ala.balti.esstt@gmail.com

Mohamed Najeh Lakhoua ENICathage, University of Carthage, Tunisia E-mail: MohamedNajeh.Lakhoua@enicarthage.rnu.tn

Imen Mhidhi National Engineering School of Carthage, ENICarthage, University of Carthage, Tunisia E-mail:mhidhiimen@outlook.fr

Cyrine Noomene National Engineering School of Carthage, ENICarthage, University of Carthage, Tunisia E-mail: cyrinenoomene3@gmail.com

Submission: $11 / 19 / 2020$

Revision: 12/15/2020

Accept: 2/2/2021

\section{ABSTRACT}

The examples of e-learning systems have been successfully tested in a number of international engineering college and innovative industry and make it possible to improve performance of production by raising the professional level of the students and staff. Elearning can directly tie education to the formation of tutorial for teaching industrial automatism, the purpose of this study is to discuss strategies for developing integrated elearning courseware based on instructional design and technology models. The essential of this methodological approach is to specify the composition of the various teaching modules in industrial automatism to be accessible to the students with a system modeling method and to develop a digital support that can be exploited in distance learning. E-learning systems aims at a two-way knowledge, communication between academia and industry. E-learning systems provides a real-life environment for engineers to develop their skills and comprehend the challenges involved in everyday industrial practice. This paper describes the challenges for using automates in the industry, It presents the fully application of system analysis for the design of a tutorial for teaching industrial automatism.

- Keywords: Courseware; Tutorial; Teaching; Industrial automatism; System analysis; E-learning 


\section{INTRODUCTION}

Much of the development of e-Learning to date has focused on basic arrangements as an effective means to make conventional education and learning methods more efficient and convenient, and some accomplishments have been realized.

The information technology (IT) revolution which began in the latter half of the 20th century has brought great changes to education and learning.

Industry requires professionals with knowledge in this field who can take advantage of the benefits of these industrial machines. In applied science education, this knowledge needs to be put into practice by means of practical labs. The new technologies have allowed to create e-learning systems, differentiated of two types, virtual and remote labs. In the virtual labs are used virtual-simulated devices, and in the remote ones, are employed real devices.

The advantage of virtual laboratory machines is that they do not require physical space, the cost is lower, and they are easily scalable (Srihi et al., 2016). Today, new learning projects and learning technologies have emerged for use with educational technologies and learning as well as for developing multimedia-based instructional design. In industry, automates are becoming more and more substantial due to their flexibility, high productivity and high quality (David \& Alla,1992).

This study examines the history and present conditions of automation in education/learning systems, centered on e-Learning, from the perspectives of information and communication technologies and instructional design.

We see a wide variation of automation like industrial instrumentation for measurement and detection, robotics industrial, industrial vision is a complex concept because there are lots of technologies and yet there will be a lot more to come which will have a remarkable effect on the industry (Cottet, 2005; Soberman, 1992).

In fact late researches have proven that emerging technologies take a huge position in the industrial world due to its plenty benefits and the new revolution of e-learning this concept has offered a whole new opportunities and new stuning ways of learning for example coursework have overcome many of the traditional limitations and offer a good source of information in the view of the above, we felt that it was necessary to create in industrial automation tutorial to ease communication and offer a new way of presenting the information (Gergely et al., 2013). 
Generally, a tutorial is classic software teaching assisted by computer to put in a situation, more or less interactive, a student and a problem to answer. This software is the specialist and deal with detailed content (robotics, industrial computers, technology...). This software is considered environments specializing in specific topics (Mu et al., 2009; Srihi et al., 2015).

The design of this application is based on an interactive conversation, and learning usually involves the center memorizing and training sequences of procedures linked with certain concepts. They are now distributed quite generally in packages to cover an exacting domain connected with a work environment that also includes dedicated tools (word processing, database, etc.) (Cade, 1993).

The tutorial is a practical tool, not only for the authors by sensitizing them to the challenges of learning computer publishing and giving them the tools to develop their mastery of traditional word processing tools, but also for the services and administrative structures that will be gradually more solicited to circulate and promote scientific production by offering models and tools for implementing computer broadcasting projects (UNESCO, 2002).

The aim of the present study is to demonstrate interests of a tutorial for teaching industrial automatism. The next section briefly presents the concepts of the tutorial then elearning. In Section 3, after presenting a systems analysis methodology based for the specification of a tutorial for industrial automatism, this approach is applied to the analysis this project. The last section presents a discussion about the impacts of this tutorial on teaching.

\section{PRESENTATION OF TUTORIALS}

Courseware (educational software) refers to a software program specially designed for educational uses. Initially available on CDs as course helps for instructors and helping them manage lectures, courseware has been revolutionized. It is now largely available online with various resources and supporting material (reference books, research papers and journals) (Chi Ng, 2006).

To measure the effectiveness of a tutorial, a representative sample of the target audience can be selected, evaluated before the tutorial by means of a pre-test, then submitted to teaching via the tutorial and finally a second evaluation. If, after the comparison between the two results obtained, it is found that certain points need to be reviewed, since the stages of 
creation are intimately linked, modifications may be made which must be adapted sequentially to the first three phases of analysis, design and construction.

Today, creating a tutorial is seen as the creative way for a problem solution. According to William Horton, the realization of a tutorial is based on 4 main stages which are: analysis, design, construction and evaluation. We can thus summarize the steps for creating a tutorial using the following flowchart (Figure 1).

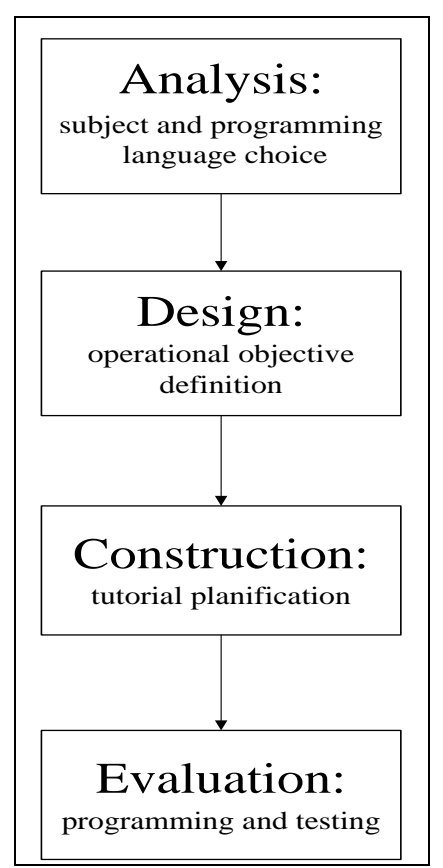

Figure 1: Realization of a tutorial with 4 main stages

The step of the analysis consists of determining the various objectives targeted through the tutorial. And To have an idea about the level of knowledge of the learners before the creation of the Tutorial. Indeed, if the courses established at the Tutorial start at a higher level, some learners will be frustrated very early on and this can discourage them. If, on the other hand, lessons start at a lower level than the learners, some may get bored and stop learning. The ideal would therefore be that the designer takes into account all these variables in order to create a Tutorial so that the learners, at each level, can start at any point or skip those deemed unnecessary. The determination of the initial level of knowledge of the learners can be done by means of questionnaires, tests, interviews, etc. (Absi et al., 2018; Lakhoua et al., 2013).

In this step of saying, the general objectives are transformed into a series of specific objectives, themselves divided into operational objectives these operational objectives are the main activities that a learner must be capable of practising them in his workplace with a certain level of performance, thanks to certain tools the learner can measure and evaluate his 
learning outcomes after setting the activities it is necessary to implement them and while the regrouping phase these activities are well combined with the objectives to create the module of the tutorial in each module we must find components that accomplish the following tasks: present the subject and the goal introduce the title and the context of the subjects summarize the main points of a module the last phase is about defining the standards, thus the designer must adjust colors, wallpapers, fonts, interface buttons and other details so that all of this contributes to the success of the learning. The designer will manage to give clear, precise and concise presentations (Absi et al., 2018).

In the last step of construction consist of creating the learning activities by selecting the appropriate technologies and creating the necessary media. The designer will have to use certain tricks and techniques to reduce the development effort, while ensuring the quality of the work (Absi et al., 2018). The evaluation phase allows us to highlight the failures and shortcomings in order to find out whether the Tutorial actually generates good results or not. To measure the effectiveness of a tutorial few samples are chosen and tested before the launch of the tutorial. One more test is required after using the courseware it aims to compare the first test result and the second so the designer can easily tell the failures of the courseware (Absi et al., 2018).

\section{The main objectives of tutorials are:}

- The acquisition of knowledge and skills.

- The procuration of know-how.

- $\quad$ The development of knowledge.

- $\quad$ The acquisition of logic.

Since the goal is to reinforce certain skills in certain fields, the courseware seemed to meet this expectation in an effective way.

In addition, it would allow operators to test themselves in order to stay on top of their skills. Indeed, the courseware offers the possibility to "refresh", and to check if they are still able to respond to the demand (Ponzanelli et al., 2018).

\section{There many types of tutorials:}

- Tutorial (Educational): it is a learning tutorial that presents screen pages with text, explanations alternated with questions that the learner must answer before continuing. The way information is presented influences the learning process 
(attention) and these processes in turn influence the learning outcome (delivery, performance);

- Exerciser: it is a tutorial consisting essentially of guidelines, statements or questions, expected answers a correction or evaluation mechanism, as well as a feedback mechanism;-

- Interactive: it is a tutorial where the activity can be free (educational games, space for exchange between learners, etc.).

\section{PRESENTATION OF E-LEARNING}

The e-learning concept is the result of information and communication technologies (network, videos, conference forums, mails, etc.) and the new training technologies (CRROM, teaching programs, tutorials, etc.) (Trekles \& Nakayama, 2010).

Learning platforms are effective tools to diffuse and manage knowledge as well as evaluate the enrolled. The major reasons for the electronic learning environment are: First, to improve the resources available for the students, second to offer a module for which an expert staff, third, to generate external revenue under distance learning programmer and finally there is no face-to-face learning, but learners are followed individually by tutoring in order to eliminate any gap related to distance (Guang \& Yan, 2011; Rotanova et al., 2018).

The design of e-learning must be applied at all units levels. It is important to understand these units because they influence what design techniques we use figure 2 describe the design all units of e-learning.

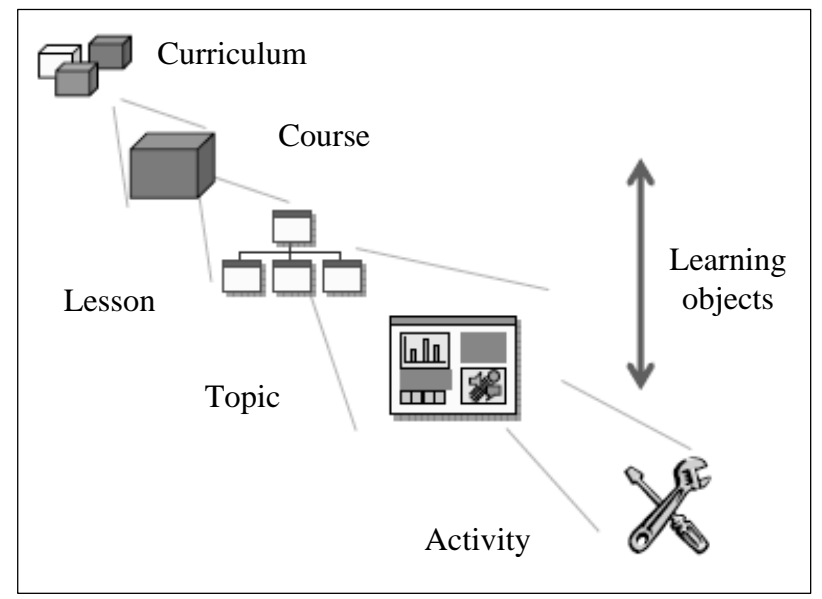

Figure 2: Design all units of e-learning Source: Horton, (2011) 
At the top of the pyramid are curricula, such as academic programs that include related courses in a subject area. A curriculum could also refer to a library of courses on a certain subject. Curricula are typically composed of courses, each of which teaches a broad but specific area of a subject. Courses are composed of clusters of smaller components called lessons. At a lower level are the individual topics, each designed to accomplish a single lowlevel learning objective. At the bottom level are learning activities, each designed to provoke a specific learning experience. Each activity may answer a specific question or make a point, but they are seldom sufficient to accomplish a learning objective by themselves.

In teaching via a tutorial, the screen is the main link with the learner. While a page may contain readable text, the screen has less text and more graphics.

The learning process involves various interrelated factors. Information becomes knowledge through the activities and then the production system of the learner, which is stimulated by motivation and interaction. The systemic loop allows this new knowledge to feed, in turn, the learning process (Ji-chun \& Jian-xin, 2018; Koroleva et al., 2018). The relationships between educational systems and integrated e-learning (IEL) are given in Figure 3.

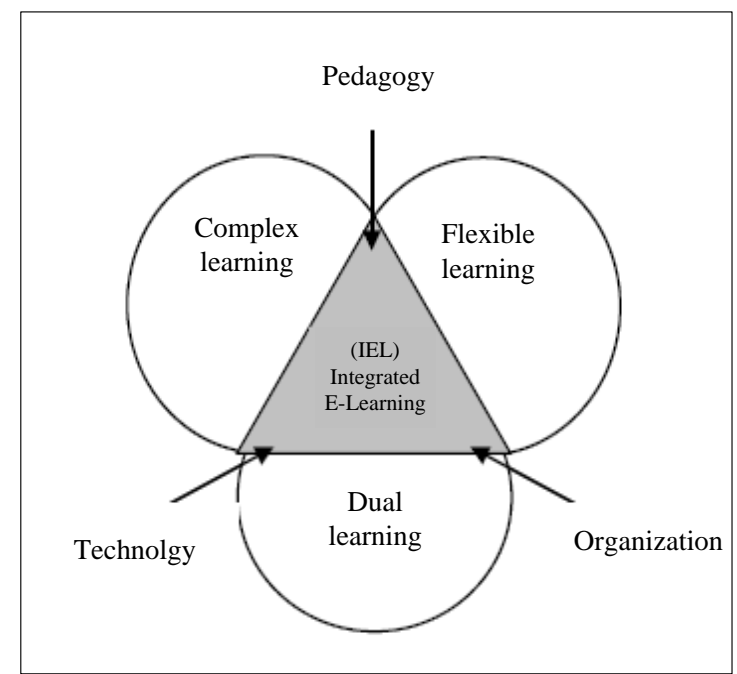

Figure 3: An Educational Systems Approach to integrated e-learning (IEL)

\section{SPECIFICATION OF A TUTORIAL}

Nowadays, the construction of a tutorial is considered to be a solution to one or many problems. It must follow certain pre-defined and necessary steps which are:

The choice of the subject and the language programming that is the preliminary point.

- The definition of the operational objectives of the tutorial. 
- $\quad$ The planning of the tutorial.

- $\quad$ The programming and testing of the tutorial.

A reflection on these points leads us to adopt a methodology which is to realize a tutorial for teaching robotics on a structured analysis (Wang et al., 2011; AGCD, 1991). This is why it is essential to identify the impact of the use of courseware in the teaching automatism. The objective of this planning methodology is to describe the diverse activities of the project. This needs identified the objectives. It is in this step to organize an integrated and predetermined configuration or to organize and change according to a plan the tutorial]. The introduction of assisted learning is the object of any production unit that aims to maximize production and minimize time since the evolution of automated systems, which makes automation one of the most innovative but also most ephemeral sectors.

Today the new industrial solutions require new didactic systems. New developments in decentralization and visualization, the introduction of the international standard IEC 131-3 as well as programming industrial controllers according to uniform rules are just a few examples of the revolution of professional sectors. In view of the huge demand it is essential today to offer modern learning systems that provide the learner with appropriate knowledge; the main objective remains the survival of companies in a rapidly changing environment (Lakhoua et al., 2020).

Focusing on courseware as a learning tool, the elaboration of a courseware can be done in several steps and we choose the OOPP method (Oriented Objective Project Planning) in order to structure our industrial automation courseware. This analysis allows us to identify four objectives.

- OS1: Presentation and planning of a tutorial for teaching industrial automatism.

- OS2: Composition of a tutorial for teaching industrial automatism.

- OS3: Programming of a tutorial for teaching industrial automatism.

- $\quad$ OS4: Test and maintenance of a tutorial for teaching industrial automatism.

They are dynamic agents who enhance the autonomous learning that students develop. Figure 4 below shows the roles (Hernandez, 2005; Lakhoua et al., 2018) depicts for an online tutor. 


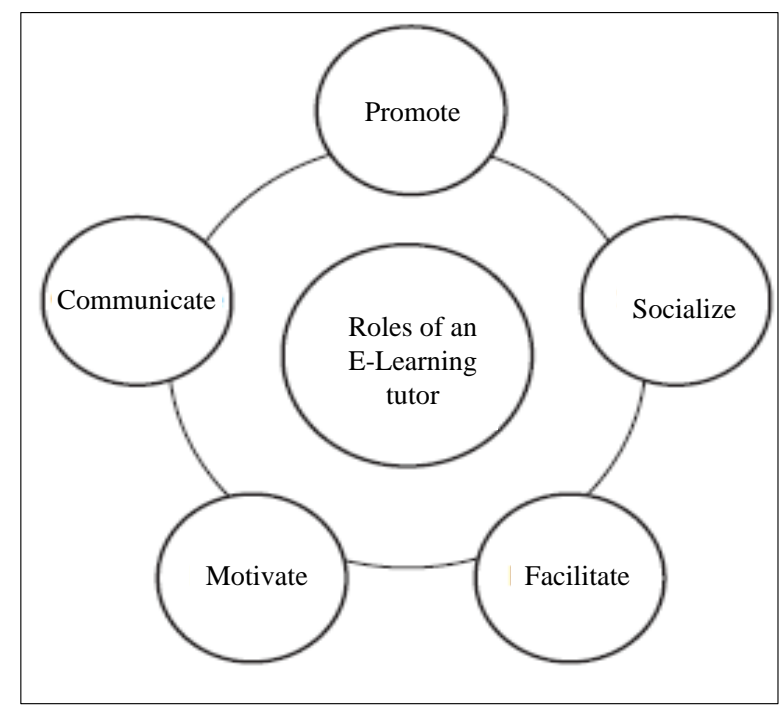

Figure 4: Roles of an E-learning tutor

We present on figure 5 the development of the objectives tree of a tutorial for teaching industrial automatism.

The tutorial corresponds to methods of transferring information and may be used as a component of a learning process. More interactive and detailed than a book or a lecture, tutorial seek to teach by example and provide the information to complete a definite task (Lakhoua, 2019).

Tutorials usually have the next characteristics (Lakhoua \& Karoui, 2020):

- A presentation of the view generally explaining and showing the user interface

- A demonstration of a process, using examples to show how a workflow or process is completed; often broken up into discrete modules or sections.

- Some method of review that reinforces or tests understanding of the content in the related module or section.

- A transition to additional modules or sections that builds on the instructions already provided. 


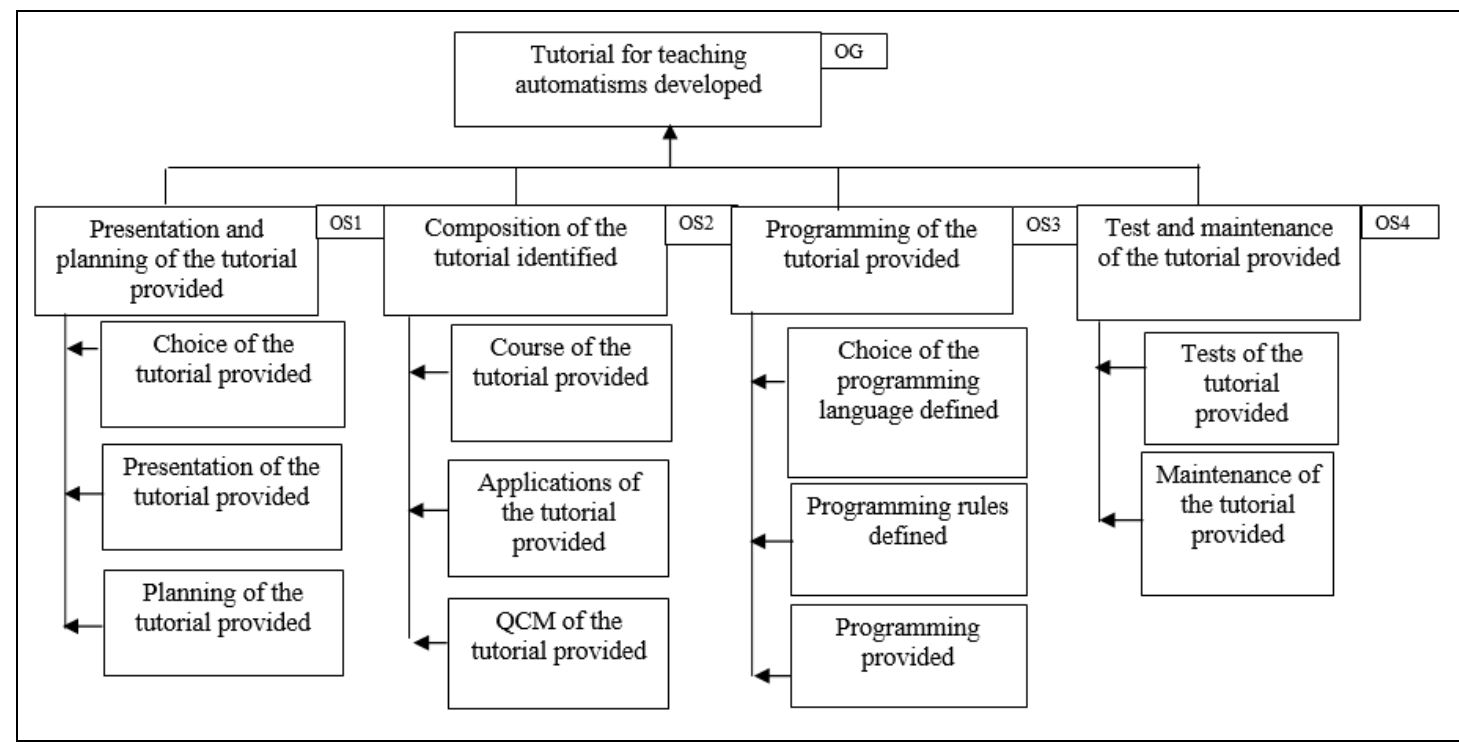

Figure 5: Tree of the objectives of the tutorial for teaching automatisms.

We can identify some added values of our prototype as a teaching aid, the first added value is the interactivity between the learner and the computer, indeed, the learner who answers a question or a set of questions receives a feedback-A quick back for each answer rather than waiting for the teacher or trainer or the end of the exercise to consult the answer key. In addition, with each answer, there is a reinforcement presented through words such as bravo, congratulations, exact, which helps to support the motivation of the learner.

The second added value of the tutorial is its ability to offer the learner work methods and cognitive and metacognitive strategies without the teacher intervening. Consequently, the learner who finds himself alone in front of the machine, is responsible for making choices that can promote his autonomy during learning. Finally, the tutorial, as a training tool, can be used to facilitate the transition from pedagogy to learners. It allows the teacher to respect the pace of learning of each of his learners, so it becomes easier for him to suggest to each activity well targeted according to the level he has reached.

\section{CONCLUSION}

This paper discusses several issues regarding the need for, and preparation of, electronic courseware. It also presents some effective strategies for the electronic delivery of modules to local and distant students especially by keeping in mind the diverse background of the students of this remote area. We present and discusses the need for electronic learning. A brief presentation of certain strategies for the preparation of electronic courseware and delivery of courses. 
So, this contribution aims to share teaching experience in higher education for teaching industrial automatism. Methods were applied to improve teaching through active tutorial. The original approach to this tutorial is the specification of the content and that by adopting a system analysis method. As a conclusion, we present the issues and outlook for the automation of education/learning systems, centered on e-Learning.

As perspectives we recommend the following: first implement the tutorial on a distance learning platform, second incorporate explanatory audio into the videos in the tutorial.

\section{REFERENCES}

Absi, R., Lavarde, M., \& Jeannin, L. (2018). Towards more efficiency in tutorials: Active teaching with modular classroom furniture and movie-making project, IEEE Global

Engineering Education Conference (EDUCON), 774-778.

AGCD (1991). Manuel pour l’application de la «Planification des Interventions Par Objectifs (PIPO)», 2ème Edition, Bruxelles.

Cade, F. H. (1993). Formation à distance, matériel pédagogique et théorie de l'éducation : la cohérence du changement, Journal of Distance Education.

Chi, Ng K. (2006). The students' views on the use of the Interwise system in distance education, 7th International Conference on Information Technology Based Higher Education and Training, 142-146.

Cottet, F. (2005). Systèmes temps réel de contrôle - commande, Dunod, Paris.

David, R., \& Alla, H. (1992). Du Grafcet aux réseaux de Petri, Paris,

Hermès, coll. « Traité des nouvelles technologies / Automatique », 2e éd, 500 p.

Gergely, E. I., Coroiu, L., \& Silaghi, H. M. (2013). Dependability Analysis of PLC I/O Systems Used in Critical Industrial Applications, Studies in Computational Intelligence, 417, 201-217.

Guang-bin, J., \& Shu-yan, S. (2011). Situation and affecting factors of online tutorial in webbased education, International Conference on Electrical and Control Engineering, 67786781.

Hernandez, A. (2005). Conceptos. La Formación sin distancia. Madrid: TT Net Espana. Servicio Publico de Empleo Estatal. Fondo Social Europeo.

Horton, W. (2011). E-learning by design. John Wiley \& Sons. 10.1002/9781118256039

Ji-chun, Z., \& Jian-xin, G., Design of distance learning streaming media system based on cloud platform, IEEE 3rd International Conference on Cloud Computing and Big Data Analysis, 2018.

Koroleva, E. A. , David, G. M., Vladimir, A. Z., Makashina, I. I., \& Filatova,, E. V. (2018). Advantages of networking and distance learning use in maritime education and training, IEEE Conference of Russian Young Researchers in Electrical and Electronic Engineering, 61-65. 
Lakhoua, M. N, Balti, A., \& Triki, R. (2013). Functional analysis and supervision of a wheighing system of a grain silo, Journal of Electrical Engineering. (ISSN: 1582-4594).

Lakhoua, M. N, Ben Salem, J., Battikh, T., \& Jabri, I. (2020). Review on Modeling and Design of Mechatronic Systems, International Journal of Mechatronics and Automation, $7(2)$.

Lakhoua, M. N. (2019). Application of System Analysis for Teaching Robotics, Annals of Robotic Surgery, 1(1), 1002.

Lakhoua, M. N., \& Karoui, M. F. (2020). Active Teaching of Project Management Through Tutorials, Sumerianz Journal of Education, Linguistics and Literature, 3(1), 1-7: 2617-1732.

Lakhoua, M. N., \& Wertani, H. (2018). Overview of Conceptual Proceedings Modeling for Complex Systems, CMSAM 2018, Wuhan China, September 27-28. [Published on the Journal of DEStech Transactions on Computer Science and Engineering].

Mu, X., Walter, D., Xu, H., Walter, P., \& Berry, C. (2009). Work in progress- video-based lab tutorials in an undergraduate Electrical Circuit course, 39th IEEE Frontiers in Education Conference, 1-2.

Ponzanelli, L., Bavota, G., Mocci, A., Oliveto, R., Penta, M., Haiduc, C. S., Russo, B., \& Lanza, M. (2018). Automatic Identification and Classification of Software Development Video Tutorial Fragments, IEEE Transactions on Software Engineering.

Rotanova, M., Fedorova, V., Kuritsyna, V., \& Saveleva, U. (2018). Distance learning as a communication strategy for educational environment formation, IEEE Communication Strategies in Digital Society Workshop.

Soberman, M. (1992). Génie Logiciel en informatique de gestion, Eyrolles, Paris.

Srihi, S., Ala Balti, A., Fnaiech, F., \& Hamam, H. (2017). Banking Security System Based on SVD Fingerprints and Cryptography Passwords, IEEE International Conference on Control, Automation and Diagnosis (ICCAD'17).

Srihi, S., Ala Balti, A., Fnaiech, F., \& Hamam, H. (2015). Information Security: Application in Business to Maximize the Security and Protect Confidential and Private Data, Automated Enterprise Systems for Maximizing Business Performance, IGI Global, 9-252015.

"https://books.google.fr/books?id=XGi2CgAAQBAJ\&lpg=PA244\&ots=POVqtIPVg4\&lr\&hl $=$ fr\&pg=PA244\#v=onepage $\& \mathrm{q} \& \mathrm{f}=$ true"

Trekles, A., \& Nakayama, S. (2010). Work in progress: Identifying adequate level of instruction without hindering deeper learning in distance learning, IEEE Frontiers in Education Conference (FIE).

UNESCO (2002). Forum sur l'impact des didacticiels libres pour l'enseignement supérieur dans les pays en développement, Rapport Final, Paris, 1-3 juillet 2002. 